\section{Commentary: When is a bidirectional cavopulmonary shunt a bad idea?}

\author{
John J. Lamberti, MD
}

In the early 1970s, Fontan and Baudet ${ }^{1}$ and Kreutzer and colleagues $^{2}$ reported successful separation of the systemic and pulmonary circulations in tricuspid atresia. Since then, surgeons and cardiologists have sought palliative procedures designed to produce the "ideal" total cavopulmonary connection (TCPC) candidate. In 1985, Hopkins and colleagues $^{3}$ reported on the efficacy of the bidirectional cavopulmonary shunt (BCPS) as a palliative procedure, thereby launching the era of staged systemic venous pathway redirection. ${ }^{4}$ In recent years, the timing and applicability of the BCPS have been adjusted to meet the needs of a growing population of complex functional singleventricle patients who are now surviving early infancy.

In 2012, the Toronto group reported directly measured superior vena cava (SVC) blood flow during the BCPS procedure. ${ }^{5}$ Low intraoperative pre-BCPS SVC flow correlated with poor clinical outcome. The current report, presented in this issue of the Journal, ${ }^{6}$ reviews all patients selected for BCPS at The Hospital for Sick Children between January 2012 and December 2017. Every patient underwent pre-BCPS cardiac catheterization, cardiac magnetic resonance imaging (CMR), and echocardiography. The methodology used for CMR data acquisition and analysis is well established, ${ }^{7}$ and the use of CMR as the primary pre-BCPS evaluation has been suggested previously. ${ }^{8}$

Univariate analysis identified moderate to severe atrioventricular valve regurgitation, pre-BCPS absolute low SVC blood flow, and prolonged cardiopulmonary

\footnotetext{
From the Division of Pediatric Cardiac Surgery, Department of Cardiothoracic Surgery, Stanford University, Stanford, Calif.

Disclosures: The author reported no conflicts of interest.

The Journal policy requires editors and reviewers to disclose conflicts of interest and to decline handling or reviewing manuscripts for which they may have a conflict of interest. The editors and reviewers of this article have no conflicts of interest.

Received for publication April 28, 2020; revisions received April 28, 2020; accepted for publication April 28, 2020; available ahead of print May 13, 2020.

Address for reprints: John J. Lamberti, MD, Division of Pediatric Cardiac Surgery, Department of Cardiothoracic Surgery, Stanford University, Falk Cardiovascular Research Center, 300 Pasteur Dr, Stanford, CA $94305-5407$ (E-mail: jlamberti@ stanford.edu).

J Thorac Cardiovasc Surg 2020;160:1543-4

0022-5223/\$36.00

Copyright (C) 2020 by The American Association for Thoracic Surgery

https://doi.org/10.1016/j.jtcvs.2020.04.144
}

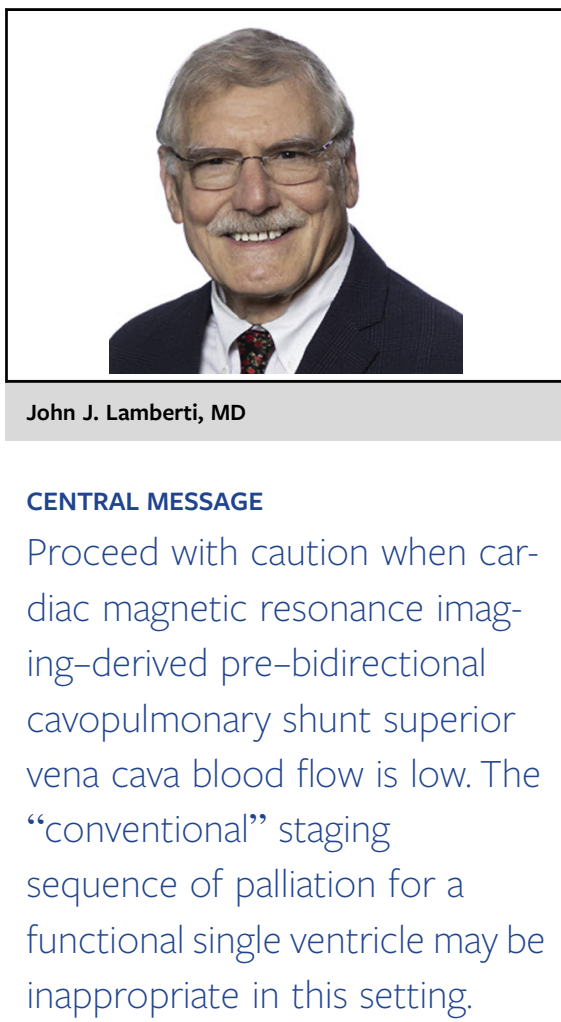

bypass $(\mathrm{CPB})$ time as risk factors for poor outcome. In multivariate analysis, only pre-BCPS indexed SVC flow was a risk factor for poor outcome.

This isolated risk factor finding is a bit surprising and somewhat counterintuitive. Is low pre-BCPS SVC blood flow an independent variable, or is it a surrogate for a complex interaction between multiple variables? The authors do not provide any information regarding the physiological status of patients during CMR. Their patient cohort is quite heterogeneous, and the previous methods of palliation are varied. Is it possible that patients palliated by the Hybrid technique, patients with hypoplastic left heart syndrome, and patients with atrioventricular $(\mathrm{AV})$ valve regurgitation (ie, patients requiring longer $\mathrm{CPB}$ time during BCPS) develop low SVC blood flow during CMR? Cerebral blood flow may be influenced by arterial $\mathrm{PCO}_{2}$ levels ${ }^{9,10}$ and other anatomic and physiological considerations. ${ }^{11}$

The adverse effect of thrombosis in the upper central venous circulation on SVC blood flow can be anticipated. We have avoided the use of internal jugular lines whenever possible in infants born with a functional single ventricle. In addition, although we recommend measuring SVC pressure at the completion of BCPS, we do not recommend leaving an indwelling jugular vein catheter in place following the procedure. 
This report is an important contribution because it calls our attention to a subset of patients that are probably not good candidates for a conventionally programmed singleventricle pathway. Low pre-BCPS SVC flow may indicate that the second-stage procedure should be designed to address the comorbid factors (eg, AV valve regurgitation, peripheral pulmonary artery stenosis) before contemplating a BCPS procedure. In essence, low pre-BCPS SVC flow may be a discriminating factor that sorts out "gray zone" candidates for BCPS. We agree with the authors' conclusion that some single-ventricle patients may be better served by early cardiac transplantation. Finally, it is worth noting that most Fontan/Kreutzer survivors over age 30 years have not undergone a BCPS procedure, indicating that it is not absolutely necessary that every patient undergo BCPS before TCPC or that all candidates for TCPC undergo the procedure before age 4 years.

\section{References}

1. Fontan F, Baudet E. Surgical repair of tricuspid atresia. Thorax. 1971;26:240-8.

2. Kreutzer G, Galíndez E, Bono H, De Palma C, Laura JP. An operation for the correction of tricuspid atresia. J Thorac Cardiovasc Surg. 1973;66:613-21.

3. Hopkins RA, Armstrong BE, Serwer GA, Peterson RJ, Oldham HN Jr. Physiological rationale for a bidirectional cavopulmonary shunt: a versatile complement to the Fontan principle. J Thorac Cardiovasc Surg. 1985;90: 391-8.

4. Lamberti JJ, Spicer RL, Waldman JD, Grehl TM, Thomson D, George L, et al. The bidirectional cavopulmonary shunt. J Thorac Cardiovasc Surg. 1990;100: 22-9; discussion 29-30.

5. Kotani Y, Honjo O, Shani K, Merklinger SL, Caldarone C, Van Arsdell G. Is indexed preoperative superior vena cava blood flow a risk factor in patients undergoing bidirectional cavopulmonary shunt? Ann Thorac Surg. 2012;94: $1578-83$.

6. Luo S, Haranal M, Deng MX, Varenbut J, Runeckles K, Fan SC, et al, Low preoperative superior vena cava blood flow predicts bidirectional cavopulmonary shunt failure. J Thorac Cardiovasc Surg. 2020;160:1529-40.e4.

7. Muthurangu V, Taylor AM, Hegde SR, Johnson R, Tulloh R, Simpson JM, et al. Cardiac magnetic resonance imaging after stage I Norwood operation for hypoplastic left heart syndrome. Circulation. 2005;112:3256-63.

8. Brown DW, Gauvreau K, Powell AJ, Lang P, del Nido PJ, Odegard KC, et al. Cardiac magnetic resonance versus routine cardiac catheterization before bidirectional Glenn anastomosis: long-term follow-up of a prospective randomized trial. J Thorac Cardiovasc Surg. 2013;146:1172-8.

9. Aeba R, Katogi T, Kashima I, Omoto T, Kawada S, Omae K. Factors influencing arterial oxygenation early after bidirectional cavopulmonary shunt without additional sources of pulmonary blood flow. J Thorac Cardiovasc Surg. 2000;120: 589-95.

10. Hoskote A, Li J, Hickey C, Erickson S, Van Arsdell G, Stephens D, et al. The effects of carbon dioxide on oxygenation and systemic, cerebral, and pulmonary vascular hemodynamics after the bidirectional superior cavopulmonary anastomosis. J Am Coll Cardiol. 2004;44:1501-9.

11. Saiki H, Kurishima C, Masutani S, Tamura M, Senzaki H. Impaired cerebral perfusion after bilateral pulmonary arterial banding in patients with hypoplastic left heart syndrome. Ann Thorac Surg. 2013;96:1382-8. 